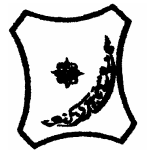

Bayero Journal of Pure and Applied Sciences, 9(2): 76 - 81

Received: May, 2016

Accepted: June, 2016

ISSN $2006-6996$

\title{
HEPATO-RENAL TOXICOLOGICAL STUDIES OF ETHYL ACETATE LEAF EXTRACT OF Vitex simplicifolia IN WISTAR RATS
}

\author{
${ }^{*}$ Salim, M.A. ${ }^{1}$ and Imam, A.A. ${ }^{2}$ \\ ${ }^{1}$ Department of Human Physiology \\ ${ }^{2}$ Department of Biochemistry
}

Faculty of Basic Medical Sciences, Bayero University Kano

*Corresponding author: zafaralisalimm@gmail.com. Phone: 08033265554

\section{ABSTRACT}

This study evaluated the hepato-renal toxicological indices following 21 days administration of ethyl acetate leaf extract of Vitex simplicifolia in Wistar rats. Acute toxicity studies with very high concentrations of the crude extract was carried out followed by sub chronic toxicities studies involving administration of $250 \mathrm{mg} / \mathrm{kg}, 500 \mathrm{mg} / \mathrm{kg}$ and $1000 \mathrm{mg} / \mathrm{kg}$ body weight of the ethyl acetate extract to the experimental animals for 21 days. Liver and Kidney toxicological indices were evaluated from the sera as well as e tissues of the experimental animals after the 21 days period of administration. The results of acute toxicity studies indicate that this extract is well tolerated at doses as high as $5000 \mathrm{mg} / \mathrm{kg}$ body weight. The results of sub-chronic toxicity studies indicate that there was a significant increase in the activities of ALP, while AST activities was significantly lower $(p<0.05)$ compared to the control. There was no significant changes in $(P<0.05)$ ALT and Unconjugated bilirubin levels in the test groups compared to the control. Similarly, the result of kidney toxicological indices showed that the levels of urea, $\mathrm{Na}^{+}, \mathrm{HCO}_{3}{ }^{2-}$ and $\mathrm{Cr}$ were significantly higher in the test animals compared to the control while $\kappa^{+}$and creatine levels showed no significant change in the extract administered groups compared to the control $(p<0.05)$. Histopathology examination of the liver and kidneys showed mild hepatic damage at the highest dose (1000 mg/kg body weight).

Keywords: Vitex simplicifolia, Hepato-renal, Toxicological Studies.

\section{INTRODUCTION}

Plants are known to be efficacious and most often could contain compounds that are potential drugs which would require further examinations .Interest in and the search for medicines from natural sources has served as a catalysts for exploring techniques of obtaining the required plants and probing their activities (Edeoga et al, 2005). A large proportion of such medicinal compounds have been discovered with the aid of ethnobotanical knowledge of their traditional uses. The rich knowledge base of countries like India and China in medicinal plants and health care has led to the keen interest by pharmaceutical companies to use this knowledge as a resource for research and development programs in the pursuit of discovering novel drugs (Krishnaraju et al., 2005). Medicinal plants have been identified and used throughout human history. Plants have the ability to synthesize a wide variety of chemical compounds that are used to perform important biological functions and to defend against attack from predators such as insects, fungi and herbivorous mammals. At least 12,000 such compounds have been isolated so far; a number estimated to be less than $10 \%$ of the total (Tapsell, et al., 2006; Lai and Roy, 2004). Chemical compounds in plants mediate their effects on the human system through processes identical to those already well understood for the chemical compounds in conventional drugs; thus herbal medicines do not differ greatly from conventional drugs in terms of how they function. This enables herbal medicines to be as effective as conventional medicines, but also gives them the same potential to cause harmful side effects (Tapsell, et al., 2006; Lai and Roy, 2004).

Vitex simplicifolia (Verbenaceae) is a perennial shrub or small tree which grows to a height of approximately $8 \mathrm{~m}$ and is widely distributed from Egypt to Guinea. In Burkina Faso, the plant is used to treat various internal or external diseases like skin diseases, dermatitis, bilharzia, migraines, fever, aches, amoebiasis, sore teeth, colic, infant tetanus (Nacoulma,1996). Investigations have also revealed that this plant is also used in the treatment of skin infections and wounds healing. In Burkina Faso, infectious diseases are the leading cause of infant $(2.37 \%)$ and maternal $(14.6 \%)$ mortality; therefore they constitute public health problems. The treatment of skin diseases dates back to ancient times, and many treatments were using medicinal plants. About $30 \%$ of traditional remedies are used to treat wounds and skin lesions, compared to only $1-3 \%$ of modern drugs (Mantle et al., 2001). The healing process is an immune response that begins after injury and takes place in three stages: vascular and inflammatory stage, phase of tissue repair and phase of maturation. A drug having simultaneously the potential antioxidant and antimicrobial activities may be a good therapeutic agent to accelerate cicatrization and wound healing (Houghton et al., 2005; Phillips et al., 1991; Heike et al., 1999). 
BAJOPAS Volume 9 Number 2 December, 2016

Aromatherapy is now considered to be another alternative way in healing people, and therapeutic values of aromatic plants lie in their volatile constituents such as monoterpenoids, sesquiterpenoids and phenolic compounds that produce a definite physiological action on the human system (Bruneton, 1993).It is locally called vitex (English), dinya birri (Hausa), Ucha koro (Igbo) and Oori-nla (Yoruba) (Burkill, 2000).

Several previous studies have established different parts of Vitex simplicifolia as a remedy against many ailments. In Nigeria, information available from the indigenous traditional healers indicates that a decoction of the chopped stem barks and leaf of Vitex Simplicifolia is prepared and taken orally for treatment of diabetes and other disease conditions. The plant extracts have been used as medication for infertility, liver disease, anodyne, stiffness, hypertension, cancer, febrifuge, as tonic galactagogue to aid milk production in lactating mothers, sedative, digestive regulator and treatment of eye troubles, kidney troubles and as supplement for lack of vitamin $\mathrm{A}$ and B (Sofowora, 1993; Burkill, 2000). Despite the extensive use of different parts of this plant for managing various ailments, to our knowledge, there has not been an extensive study of its possible toxicity against any organ or the whole system. The aim of this study therefore is to investigate the toxicological effect of ethyl acetate extract of Vitex simplicifolia leaf on the liver and kidney.

\section{Material and Methods}

\section{Plant and animal}

The leaves of Vitex simplicifolia were collected from Bayero University Kano and were dried in shade at room temperature and grounded into powder. Wistar rats were obtained from the Department of Physiology Animal house, Bayero University Kano. The rats were housed in colony cages at an ambient temperature and relative humidity. The animals had free access to standard palletized grower feed and drinking water.

\section{Extract preparation}

The powdered plant $(100 \mathrm{~g})$ was dissolved in $1000 \mathrm{ml}$ ethyl acetate overnight. It was filtered and the residue was discarded. The filtrate was evaporated to dryness using Vacuum evaporator. The dried plant residue was used to prepare different concentrations.

\section{Experimental Design}

A total of 33 Wister rats were used for the study. Thirteen (13) rats were used for the acute toxicity study while 20 rats were used for the sub-chronic toxicity study. For the sub-chronic toxicity study, the 20 animals were divided into four groups of five rats each. Group 1 was the control fed only feed and water throughout the period of the experiment while groups 2, 3, and 4 were administered 250, 500 and $1000 \mathrm{mg} / \mathrm{kg}$ body of the ethyl acetate extract respectively for 21 days. After the 21 days of administration, the animals were sacrificed, blood samples were collected in heparin bottles and the liver and kidney of the animals were removed and preserved in $9 \%$ formalin until histopathological analysis.
Determination of $\mathbf{L D}_{\mathbf{5 0}}$

The lethal dose $\left(\mathrm{LD}_{50}\right)$ was determined by the method of Lorke (1983).In the first phase,

Nine (9) Wister rats were used. The nine animals were divided into three groups of three animals each. Each group were administered 10,100 and $1000 \mathrm{mg} / \mathrm{kg}$ body weight of the extracts and then observed for 24 hours to monitor their behaviour and mortality. In the second phase two of the experiment, three animals were used; the animals were divided into three groups of one animal each. They were administered highier doses (1600, 2900 and $5000 \mathrm{mg} / \mathrm{kg}$ body weight) of the extracts and observed for behaviour as well as mortality. (Lorke, 1983). $\mathrm{LD}_{50}$ was calculated by the formula: $L D_{50}=\sqrt{ }\left(D_{0} \times D_{100}\right)$ where:

$D_{0}=$ Highest dose that gave no mortality,

$\mathrm{D}_{100}=$ Lowest dose that produce mortality.

\section{Liver and Kidney function test}

Four enzymes indices of liver damage were assayed to determined liver toxicity. ALP activity was determined by the method described by Karmen, (1955), AST and ALT activities were determined by the methods of Reitman and Frankel (1957) while bilirubin levels was determined by the method of Sherloch (1951). Kidney function was evaluated by determining the levels of kidney function indices; urea, creatinine, sodium ion, potassium ion, chloride ion and bicarbonate ion using the methods described by Henry (1974) and White (1970).

Histopathological studies (Avwioro, 2010; Mitchell et al., 2011)

The liver biopsies were fixed with $10 \%$ formal saline and then transferred to a cassette, a container designed to allow reagents to freely act on the tissue inside. This cassette was immersed in multiple baths of progressively more concentrated ethanol (to dehydrate the tissue with ascending grade of alcohol), cleared with toluene, infiltrated with molten paraffin wax. During this 12 to 16 hour process, paraffin will replace the water in the tissue, turning soft, moist tissues into a sample miscible with paraffin, a type of wax. This process is known as tissue processing. The processed tissue was then taken out of the cassette and set in a mold. Additional paraffin was added to create a paraffin block which is attached to the outside of the cassette. The process of embedding allows the sectioning of tissues into very thin (2- 7 micrometer) sections using a microtome. The slices are thinner than the average cell, and are layered on a glass slide for staining. Tissue was dewax and hydrated, stained in Erich's haematoxylin for 15mins, rinsed in water, differentiated in $1 \% \mathrm{HCl}$ and $70 \%$ alcohol for $1 \mathrm{~min}$, rinsed in water, counterstained with $1 \%$ eosin for $1 \mathrm{~min}$, rinsed in water again and finally dehydrated, cleared and mounted on microscope for examination.

\section{STATISTICAL ANALYSIS}

The results obtained are presented as Mean \pm standard error of mean (SEM). A one way analysis of variance (ANOVA) was used for the data analysis. Significant differences between groups were detected in the ANOVA using Bonferini test at $P$ values less than 0.05 and 0.001 .Using SPSS 20 Soft ware package for windows 
Results

The results of phase I and II acute toxicity studies is presented in Tables 1 and 2 below. In both phases no signs of toxicity or mortality were recorded after 24 hours of the administration.

Table 1: Phase I LD 50 , of the ethyl acetate leaf extract of Vitex simplicifolia

\begin{tabular}{|l|l|l|l|}
\hline Group & No. of Animals & Doses $\mathbf{( m g / K g ~ )}$ & No. of Death \\
\hline 1 & 3 & 10 & 0 \\
\hline 2 & 3 & 100 & 0 \\
\hline 3 & 3 & 1000 & 0 \\
\hline
\end{tabular}

Table 2: Phase II LD LD $_{50}$ of the ethyl acetate leaf extract of Vitex simplicifolia

\begin{tabular}{|l|l|l|l|}
\hline Group & No. of Animals & Doses $\mathbf{( m g / K g ~ )}$ & No. of Death \\
\hline 1 & 3 & 1600 & 0 \\
\hline 2 & 3 & 2900 & 0 \\
\hline 3 & 3 & 5000 & 0 \\
\hline
\end{tabular}

Table 3 below shows the activities of AST, ALT, ALP and unconjugated billirubin in extract administered and control rats. ALP and ALT significantly $(P<0.05)$ increased in the test groups (Groups II, III and IV) compared to the control. The activity of AST between the test and control groups did not change significantly. Similarly, the levels of unconjugated billirubin were not significantly different $(p<0.05)$ from the control.

Table 3: Effect of oral administration of ethyl acetate of leaf extract of Vitex simplicifolia on liver enzymes of rats.

\begin{tabular}{cccll}
\hline GROUP & ALP/ $(\mathbf{U} / \mathbf{I})$ & AST/ $(\mathbf{U} / \mathbf{I})$ & ALT/ $(\mathbf{U} / \mathbf{I})$ & U.Bil $(\boldsymbol{\mu m o l} / \mathbf{I})$ \\
\hline 1 & $200.33 \pm 7.84$ & $84.667 \pm 4.70$ & $39.00 \pm 3.05$ & $1.148 \pm 0.325$ \\
2 & $575.00 \pm 16.86^{\mathrm{a}}$ & $74.13 \pm 1.03$ & $53.00 \pm 0.57^{\mathrm{a}}$ & $2.367 \pm 0.3$ \\
3 & $171.00 \pm 1.00$ & $23.00 \pm 1.00^{\mathrm{a}}$ & $41.00 \pm 1.00$ & $0.84 \pm 0.09$ \\
4 & $647.00 \pm 6.00^{\mathrm{a}}$ & $0.424 \pm 0.30^{\mathrm{a}}$ & $50.50 \pm 1.50^{\mathrm{a}}$ & $0.53 \pm 0.070$ \\
\hline
\end{tabular}

Grp 1: Control, Grps 2, 3 and 4 received 250, 500 and $1000 \mathrm{mg} / \mathrm{kg}$ of extract, respectively. Values are presented as mean \pm standard error of mean. Values bearing superscript 'a' are significantly different $(p<0.05)$ from the Normal control.

The result of kidney toxicological indices following administration of ethyl acetate leaf extract of Vitex simplicifolia is presented in table 4 . Sodium, chloride, urea and carbonate levels of the test animals showed significant $(P<0.05)$ increase compared to that of the control However, the concentration of potassium and creatine did not differ significantly $(P>0.05)$ between the test and the control groups.

Table 4: Effect of oral administration of ethyl acetate fraction of leaf extract of Vitex simplicifolia on urea, creatinine and electrolytes in rats.

\begin{tabular}{ccllccc}
\hline Groups & $\begin{array}{c}\text { Urea } \\
(\mathbf{m g} / \mathbf{d l})\end{array}$ & $\begin{array}{l}\text { Creatinine } \\
(\boldsymbol{\mu m o l} / \mathbf{I})\end{array}$ & $\begin{array}{c}\mathbf{N a}^{+} \\
(\mathbf{~ m E q} / \mathbf{L})\end{array}$ & $\begin{array}{c}\mathbf{K}^{+} \\
(\mathbf{m E q} / \mathbf{L})\end{array}$ & $\mathbf{C l}^{-}(\mathbf{m E q} / \mathbf{L})$ & $\begin{array}{c}\mathbf{H C O}_{\mathbf{3}}^{-} \\
(\mathbf{m E q} / \mathbf{L})\end{array}$ \\
\hline 1 & $25.72 \pm 0.83$ & $186.33 \pm 3.18$ & $219.48 \pm 2.31$ & $5.86 \pm 0.80$ & $75.71 \pm 1.04$ & $44.33 \pm 1.45$ \\
2 & $156.62 \pm 3.10^{\mathrm{a}}$ & $158.61 \pm 3.10^{\mathrm{a}}$ & $190.43 \pm 3.31^{\mathrm{a}}$ & $3.73 \pm 0.15$ & $88.37 \pm 1.52^{\mathrm{a}}$ & $24.33 \pm 1.20^{\mathrm{a}}$ \\
3 & $122.61 \pm 2.00^{\mathrm{a}}$ & $125.00 \pm 2.00^{\mathrm{a}}$ & $243.61 \pm 3.00^{\mathrm{a}}$ & $3.54 \pm 0.10$ & $80.78 \pm 1.00$ & $42.00 \pm 2.00$ \\
4 & $77.27 \pm 1.29^{\mathrm{a}}$ & $147.00 \pm 2.00^{\mathrm{a}}$ & $244.94 \pm 2.15^{\mathrm{a}}$ & $5.18 \pm 2.1$ & $88.30 \pm 0.64^{\mathrm{a}}$ & $42.00 \pm 1.00$ \\
\hline
\end{tabular}

Grp 1: Control, Grps 2, 3 and 4 received 250, 500 and $1000 \mathrm{mg} / \mathrm{kg}$ of extract, respectively. Values are presented as mean \pm standard error of mean. ${ }^{a}=$ significantly different $(p<0.05)$ from the Normal control.

Plates I and II below showed the result of liver histopathological examination of the control and group IV administered $1000 \mathrm{mg} / \mathrm{kg}$ body weight of the ethyl acetate leaf extract of the plant. The liver architecture of the control group showed no pathological changes, while that of the test group show mild fatty change, moderate sinusoidal lymphocytosis, with prominent kupfer cells. 


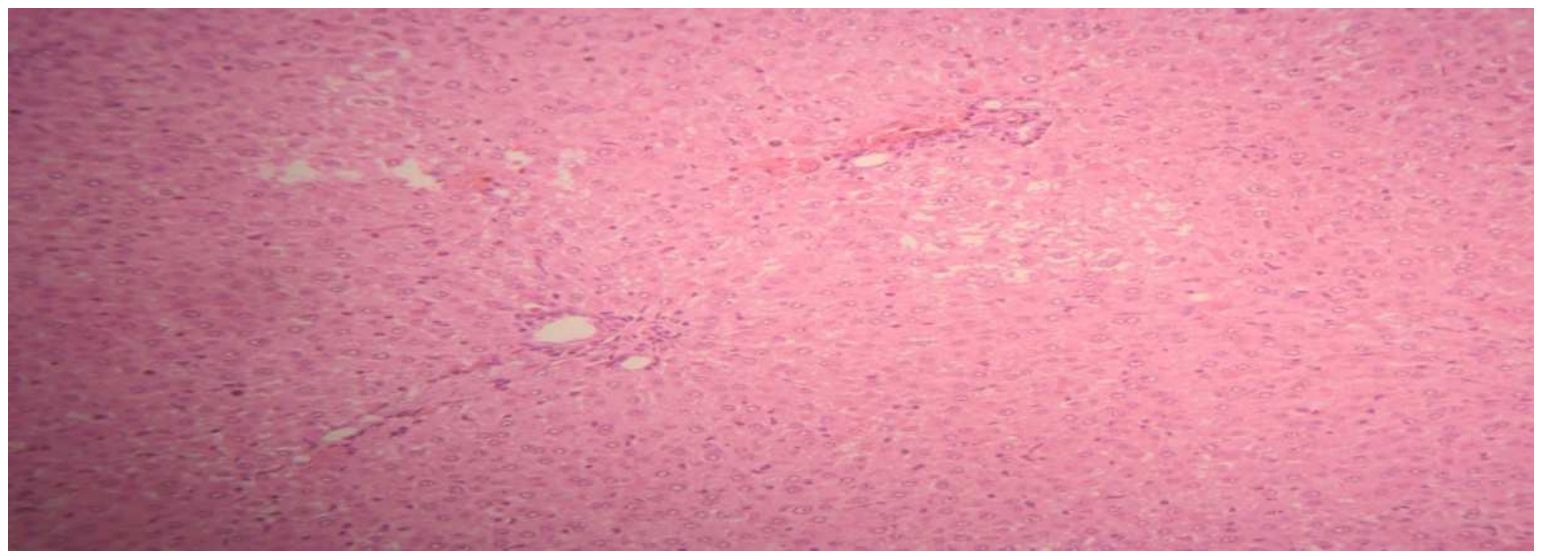

Plate 1: Stained cross section of liver of group I (control) Wister rats administered no extract showing the portal tract area, with no pathological changes (normal). (H and E Stain $(\times 250)$

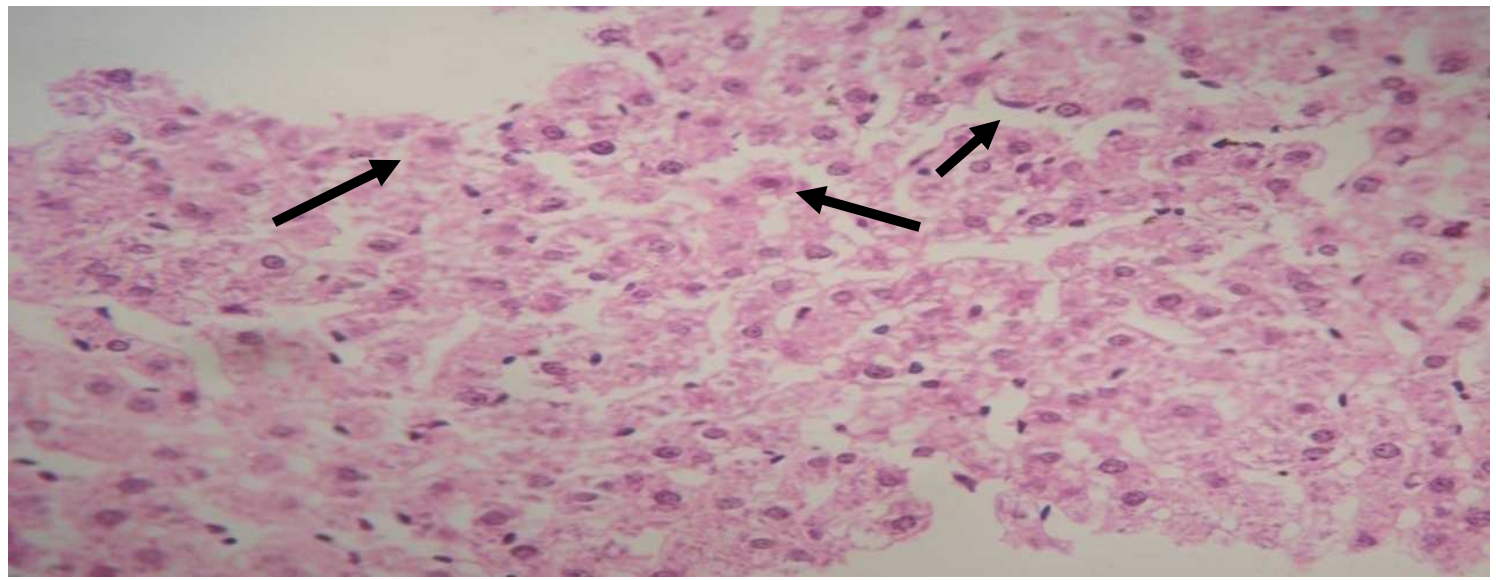

Plate II: photomicrograph of a section of liver from wister rats administered ethyl acetate fraction of Vitex simplicifolia leaf extract for twenty one days using $\mathrm{H}$ and $\mathrm{E}$ stain and a magnification of $\mathrm{x} 250$. This shows the portal tract area(black arrows), with mild fatty change, moderate sinusoidal lymphocytosis, with prominent kupfer cells

Plates III and IV below showed the result of kidney histopathological examination of the control (Group I) and test group IV administered $1000 \mathrm{mg} / \mathrm{kg}$ body weight of the ethyl acetate extract of the plant. The kidney architecture when compared to the group I control showed lining epithelia demonstrating hydropic swelling in the $1000 \mathrm{mg} / \mathrm{kg}$ body weight extract administered rats.

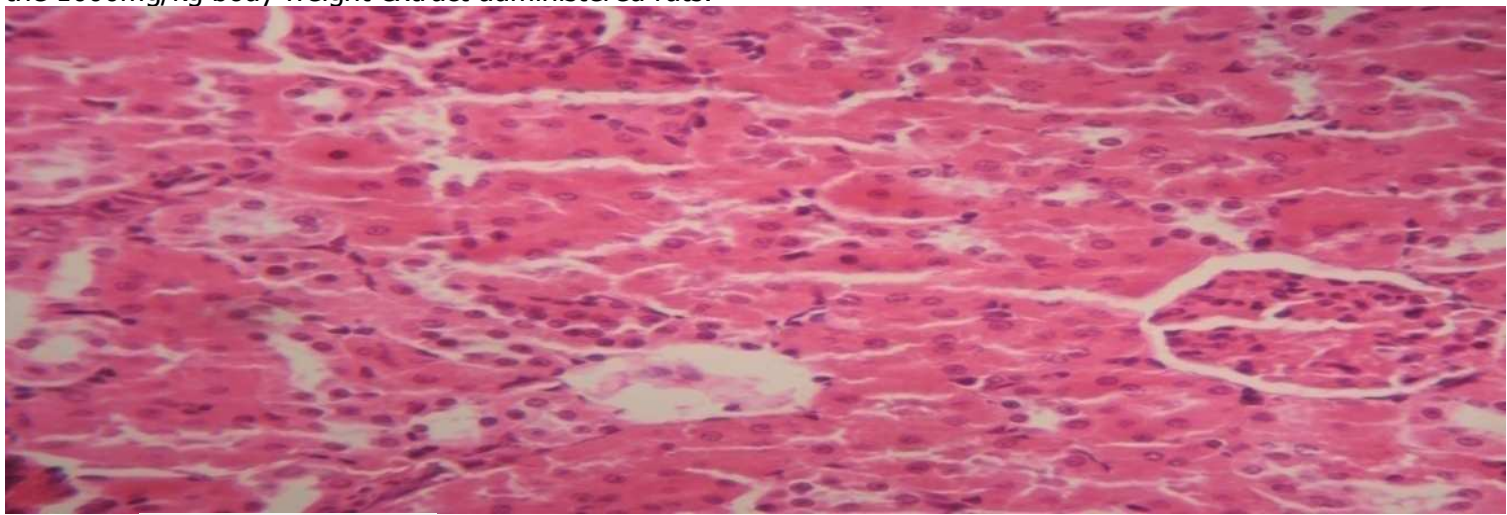

PlateIII : Photomicrograph of a cross section of kidney of group I (control) Wister rats administered no extract showing the portal tract area, with no pathological changes (normal). ( $\mathrm{H}$ and E Stain $(\times 250)$. 


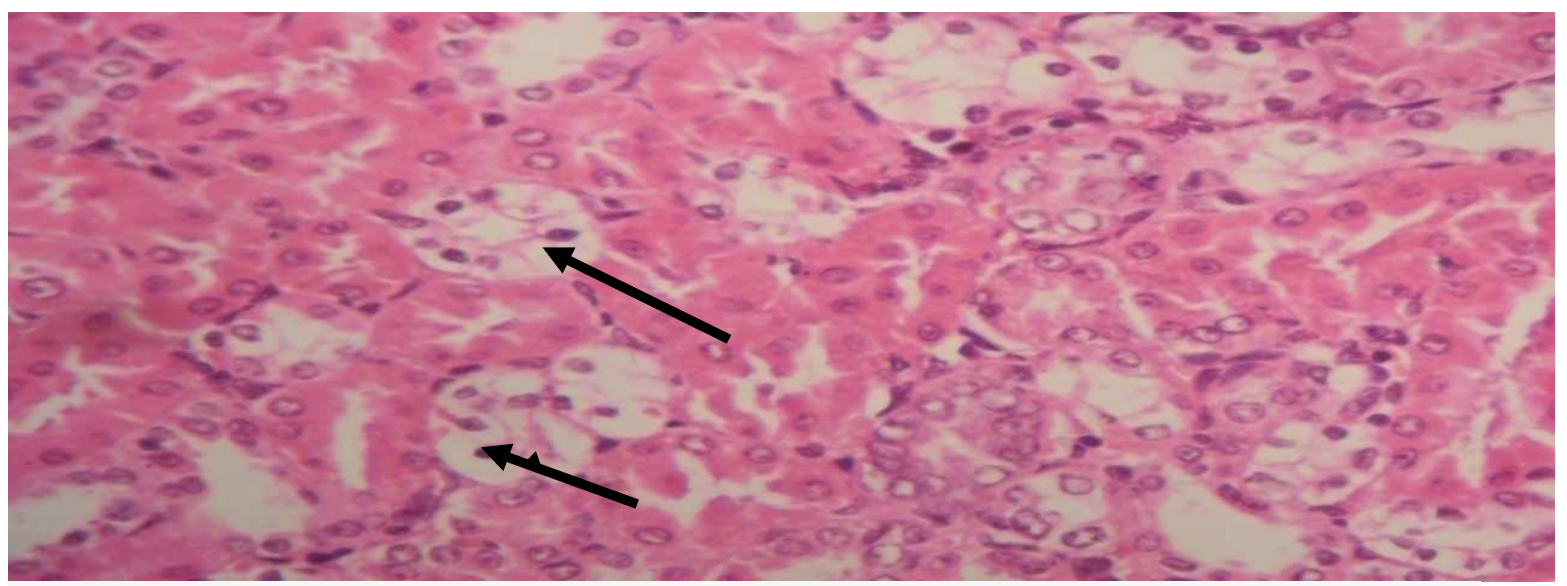

Plate IV: Photomicrograph cross section of kidney from diabetic Wister rat administered $1000 \mathrm{mg} / \mathrm{kg}$ of ethyl acetate fraction of Vitex simplicifolia leaf extract for twenty one days using $\mathrm{H}$ and $\mathrm{E}$ Stain and magnification of $\times 250$. This shows medulla of the kidney (black arrows) with several tubules and lining epithelia demonstrating hydropic swelling

\section{DISCUSSION}

The administration of ethyl acetate leaf extracts of Vitex simplicifolia at 250, 500 and $1000 \mathrm{mg} / \mathrm{kg}^{-1}$ doses for 21 days orally was observed to significantly increase ALP $(P>0.05)$ and decrease significantly $(P>0.05)$ AST and had no significant change on the activity level of ALT and unconjugated billirubin. The elevation of levels of alkaline phosphatase (ALP) as observed in the present study may be an indication of either liver problem or bone disease, since the two main sources of ALP are liver and bone. ALT is a cystosolic enzyme more specific to the liver, so a rise only occurs with liver diseases (Amdar et al., 1998). Although high level of serum bilirubin is used as indices of liver function and bile excretion status (Abdurrahman et al, 2007), this study did not record appreciable differences in bilirubin levels between the test and the control groups.

The administration of ethyl acetate leaf extract of Vitex simplicifolia to Wistar rats showed significant increase $(p<0.05)$ in sodium, urea, chloride and carbonate but no significant change $(p<0.05)$ in potassium and creatinine levels. The elevation of serum urea observed in this study may have resulted

\section{REFERENCES}

Avwioro, O.G. (2010). Histochemistry and Tissue Pathology: Principles and Techniques $2^{\text {nd }}$ edition. University Press Delta State University, Abraka Nigeria metabisulphite on the integrity of rat cellular system. Toxicology;81:173-179. retrieved fromhttp://www.labtestsonline.org/understa nding/analytes/creatinine/test

Bruneton, J.,(1993). Pharmacognosy, phytochemistry, Medicinal Plants. 2nd Tech and Doc.

Burkill HM (2000). Useful Plants of WestTropical Africa. 2nd ed. Vol. 5. Royal Botanic

Butyrospermun paradoxum in laboratory animals. PhD Thesis, University of from kidney damage from exposure to the extract. It is an established fact that a wide variety of renal diseases with different permutation of glomerular, tubular, interstitial or vascular damage can cause an increase in serum urea concentration (Roct et al., 1998). Histopathology result of the kidney (Plate IV) with distal tubular damage substantiate this observation. Urea is a by product of protein metabolism that is excreted through the urine (Abdulrahman et al., 2007). Previous studies(Rabo, 1998 and Abdulrahman et al.,2006) on Vitex donniana; a related specie of Vitex simplicifolia reported similar observations which indicate that the Vitex family may contain some phytochemicals that could induce mild damage to the kidney.

\section{Conclusion}

This study evaluated hepato-renal toxicological indices following oral administration of ethyl acetate leaf extract of Vitex simplicifolia to experimental animals. The recorded observations suggest that the plant is well tolerated up to a dose of $5000 \mathrm{mg} / \mathrm{kg}$ body weight at acute level but produced a sub-chronic injury to the liver and kidney. Thus care should be exercised when using this plant as a phytoremedy against ailments.

Cragg G M., Newman D.J. (2001). Medicinal for the Millennia. Annals of the New York Academy of Sciences 953: 3-25.

Edeoga, H.O,Okwu,O.E and M Bade (2005). Phytochemical constituents of some Nigerian Medicinal plants.Afr.J.Biotechno.,4:685- 688.

Heike, S., Munz, B., Werner, S., Brauchle, M., (1999). Different types of ROS-scavenging enzymes are expressed during cutaneous wound repair. Experimental Cell Garden Kew. pp 272-275

Henry R.F. (1974). Clinical Chemistry Principles and Technics, $2^{\text {nd }}$ Edition, Harper and Row, Hagerstein M.D. p20-23 
Karmen, A Wroblewski, F and LaDue, J S (1955). Commentary to transaminase activity in human blood. Journal of Clinical Investigation 34(1):126-133

Krishnaraju, A.V., Rao, TVN., Sundararajua, D., Vanisreeb, M., Tsayb, H.S., and Subbarajua, G.V. (2005). Assessment of bioactivity of Indian medicinal plants using brine shrimp (Artemia salina) lethality assay. International Journal of Applied Science and Engineering 2: $125-134$.

Lai P.K., Roy J. (2004). "Antimicrobial and chemopreventive properties of herbs and spices". Curr. Med. Chem. 11 (11): 145160. d oi:10.2174/0929867043365107. PMID 15180 577.

Lavoisier Paris p915

Lorke, D. (1983). A New Approach to Practical Acute Toxicity Testing. Arch. Maiduguri, Maiduguri, Nigeria. p34-56

Mantle, D., Gok ,M.A., and Lennard T.W.J. (2001). Adverse and beneficial effects of plant extracts on skin and skin disorders. Adverse Drug Reactions and Toxicological Reviews 20(2): 103-89

Mitchell, S. Sheppard, R., Vinay, K., Abbas, A., Abul, K. and Fausto, Nelson. R. (2011). Basic Pathology. 8th edition. Chapter 11 Philadelphia: Saunders.

Nair R, Chanda S (2007). Antibacterial activities of some medicinal plants of the Western region of India. Turkish Journal of Biology 31: 231236.
Phillips, G.D., Whitehe, R.A., and Kinghton, D.R. (1991). Initiation and pattern of angiogenesis in wound healing in the rat. American Journal of Anatomy 192:257-262

Rabo, J.S.(1998). Toxicity studies and trypano suppressive effects of stem- back extracts of

Reitman S., and Frankel S (1957). Colorimetric method for the determination of serum glutamic oxaloacetate and glutamic pyruvic transaminases.. Amer J. Clin Path 28:56.

Roct, R.C, W.G. Walker and C.D. Jennings(1998).Nitrogen Metabolites and Renal Function.:

Sharma A, Shanker C, Tyagi L, Singh M, Rao CV (2008) Herbal Medicine for Market Potential in India: An Overview. Academic Journal of Plant Sciences 1: 26-36.

Sofowora, A. (1993). Medicinal Plants and Traditional Medicine

in

Africa.2ndEdn.,SpectrumBooks,Nigeria,ISBN1 3:9789782462190,pp142-144

Tapsell LC, Hemphill I, Cobiac L, et al. (2006). "Health benefits of herbs and spices: the past, the present, the future". Med. J. Aust. 185 (4 Suppl): S4-24. PMID 17022438.

Textbook of Clinical Chemistry. Tiez,N.W(ED),W.B. Saunders Company, Philadelphia,

White W.L. (1970). Chemistry for Technologist, $3^{\text {rd }}$ Ed. The C.V Mosby Co., St. Louis p. 182 